1 MacMillan AL Generalised pustular drug rash Dermutologica 1973:146:285-91.

Beylot C. Bioulac D, Doutre MS. Pustuloses exanthemiques aigues generalisees. Ann Dermatol Venereol $1980 ; 107: 37-48$.

3 Stoughton CME, Harper JI, McMichen H. Toxic pustuloderma-a new entity? $\mathcal{F} R$ Soc Med 1984;77 (suppl 4:6-8

4 Tan RS-H. Acute generalized pustular bacterid. Br f Dermatol 1974;91:209-15.

Lawson DH, Paice J. Adverse reactions to trimethoprim-sulphamethoxazole. Rev Infect Dis $1982 ; 4: 429-33$

(Accepted 13 August 1986)

Skin Hospital, Manchester M3 3HL

K J S MACDONALD, MRCP, FRACP, senior registrar

Department of Dermatology, Ninewells Hospital, Dundee DD1 9SY

C M GREEN, MB, MRCP, registrar

K J A KENICER, MB, MRCP, consultant dermatologist

Correspondence to: Dr Macdonald.

\section{Blood cotinine, carboxyhaemoglobin, and thiocyanate concentrations and cigarette consumption}

It is important that doctors should be aware of the correlation between patients' blood concentrations of tobacco products, reported cigarette

\section{Comment}

Among the abstainers at six months there was a significant reduction i blood concentrations of the three analytes compared with those of the nonc smokers. In the continuing smokers, however, blood concentration§ remained unchanged from measurements at entry. The blood tests wer particularly useful in identifying false reporting of cigarette consumption Two of the group reporting abstention at six months had concentration $\$$ suggesting continued smoking and subsequently admitted to false reporting

When cigarette consumption at entry was categorised into heavy and lighe to moderate we found that heavy smokers had significantly higher blood: concentrations of the three analytes than light to moderate smokers. These results, however, were aggregations of data based on broad categories, ant other workers have found low correlations between reported numbers of cigarettes smoked and biochemical measurements. ${ }^{3} 4$

In addition to actual cigarette consumption, blood concentrations of tobacco products vary with depth of inhalation, frequency of puffing? proportion of each cigarette consumed, time between smoking and bloo sampling, absorption, rates of transfer in the tissues, and metabolism and excretion of tobacco products. ${ }^{4} 5$ In our study time of blood sampling from the last cigarette made minimal contribution to the blood concentrations $\vec{s}$ ( $13 \%$ for carboxyhaemoglobin, $1 \%$ for thiocyanate, $10 \%$ for cotinine).

We emphasise that in our study the relation between cigarette consumpotion and blood concentrations was examined retrospectively. This should be explored more carefully in a prospective study with larger numbers of smokers categorised into smaller groupings of cigarette consumption.

Interestingly, we found that subjects with lower cigarette consumptioioj and lower blood concentrations were more successful at stopping smokinge Though nicotine in cigarettes is regarded as the main component of dependence, the blood concentrations of all three analytes in our study werê related to outcome.

Concentrations of cotinine, carboxyhaemoglobin, and thiocyanate

\begin{tabular}{|c|c|c|c|c|c|c|c|}
\hline \multirow[b]{2}{*}{ Smoking state } & \multirow[b]{2}{*}{ No } & \multicolumn{2}{|c|}{ Cotinine $(\mathrm{nmol} / \mathrm{l})$} & \multicolumn{2}{|c|}{ Carboxyhaemoglobin (\%) } & \multicolumn{2}{|c|}{ Thiocyanate $(\mu \mathrm{mol} / \mathrm{l})$} \\
\hline & & Mean & SD & Mean & SD & Mean & SD \\
\hline $\begin{array}{l}\text { Non-smokers } \\
\text { Light to moderate smokers }\end{array}$ & 198 & 23 & 76 & 0.93 & 0.5 & 33 & 15 \\
\hline (at entry) & 56 & 1430 & 1090 & 3.47 & 1.8 & 98 & 40 \\
\hline Heavy smokerst (at entry) & 132 & 2107 & 1304 & $4 \cdot 85$ & $2 \cdot 1$ & 114 & 47 \\
\hline Abstainers (at 6 months) & 34 & 60 & 181 & 1.03 & 0.5 & 44 & 18 \\
\hline
\end{tabular}

$\star 1-19$ Cigarettes daily

$t \geqslant 20$ Cigarettes daily.

Conversion: SI to traditional units_Cotinine: $1 \mathrm{nmol} / \mathrm{l} \approx 17 \cdot 6 \mathrm{ng} / 100 \mathrm{ml}$. Thiocyanate: $1 \mu \mathrm{mol} / \mathrm{l} \approx 5 \cdot 8 \mu \mathrm{g} / 100 \mathrm{ml}$.

consumption, and success in stopping smoking. We report these correlations as part of a study of patients attending a stop smoking programme administered by general practitioners. ${ }^{1}$ In that study smokers were randomly allocated to either a treatment $(n=100)$ or control group $(n=100)$ and baseline data collected on 200 non-smokers. The structured personalised programme is described elsewhere. ${ }^{2}$ At three years $36 \%$ of the treated smokers were abstinent, self reports being validated biochemically by salivary cotinine estimations.

\section{Patients, methods, and results}

Of the 200 smokers and 200 non-smokers studied, 188 and 198 respectively had blood tests at entry. At six months only the smokers at entry had a second blood test, assays being performed on 34 abstainers and 81 continuing smokers. The remaining 73 subjects comprised 25 continuing smokers who refused to give blood and 48 participants lost to follow up. An abstainer was a previous smoker who had not smoked for at least three months before the visit at six months, and a continuing smoker a regular or occasional smoker or dropout from the study.

A $10 \mathrm{ml}$ blood sample was obtained from each participant, $2 \mathrm{ml}$ being stored as whole blood for carboxyhaemoglobin assay. Plasma cotinine estimations were by gas chromatography, carboxyhaemoglobin estimations by automated spectrophotometry, and plasma thiocyanate estimations by ion chromatography. Methods of analysis were as reported. ${ }^{2}$ Plasma thiocyanate analysis at six months was performed with a different resin from the initial assay, giving higher values than at entry.

At entry the blood concentrations of cotinine, carboxyhaemoglobin, and thiocyanate in non-smokers were significantly less than those in smoker $(p<0.0001$ in each case; table). Moreover, the concentrations of all three analytes in smokers were related to their cigarette consumption, heavier smokers having significantly higher concentrations than light to moderate smokers $(p<0.0001$, $\mathrm{p}<0.0001$, and $\mathrm{p}<0.05$ respectively). Abstainers at six months, who came from both groups of smokers at entry, had concentrations of analytes that were not significantly different from those of non-smokers. Smokers who became abstainer generally had lower concentrations of these components at entry than those who continued to smoke.
We thank Dr D R Richmond for advice and the department of biochemistry Royal Prince Alfred Hospital, for assaying the blood samples.

1 Richmond RL, Austin A, Webster IW. Three year evaluation of a programme by genera practitioners to help patients to stop smoking. Br Med f 1986;292:803-6. practitioners to help patients to stop smoking. Br Med 7 1986;292:803-6.
Richmond RL, Webster IW. A smoking cessation programme for use in general practice. Med
Aust 1985;142:190-4.

3 Russell MAH. Cigarette consumption and biochemical measures of smoke intake. $\mathrm{Br}$ Med 1982;285:507.

4 Schachter S. Nicotine regulation in heavy and light smokers. F Exp Psychol (Gen) 1977;106:5-12

5 Russell MAH. Nicotine intake and its regulation. F Psychosom Res 1980;24:253-64.

(Accepted 29 August 1986)

South Wales, Kensington, Sydney, NSW 2033, Australia

ROBYN RICHMOND, MA, PHD, senior lecturer

IAN WEBSTER, MD, FRACP, professor

Correspondence to: Dr Richmond.

\section{Correction}

\section{Exposure of midwives to nitrous oxide in four hospitals}

We regret that in this paper ( 25 October, p 1063) three lines were misplaced. The first two sentences of the second paragraph of the discussion should readi "Workload does not appear to be a contributing factor as hospitals A and B exceef hospital $\mathrm{D}$ in this respect (table). The smaller proportion of deliveries performect under epidural analgesia in hospital D than in hospital A or C is a possible factor.' 